\title{
Aegla rosanae Campos Jr., um novo sinônimo de Aegla paulensis Schmitt (Crustacea, Aeglidae) ${ }^{1}$
}

\author{
Georgina Bond-Buckup 2, 3 \\ Ludwig Buckup ${ }^{2}$
}

\begin{abstract}
Aegla rosanae Campos Jr., a new synonym of Aegla paulensis Schmitt (Crustacea, Aeglidae). The validity of Aegla rosanae Campos Jr., 1998 as a new species was analysed. On the basis of comparisons with Aegla paulensis Schmitt, A. rosanae was considered its junior synonym.

KEY WORDS. Crustacea, Aegla, South America, taxonomy
\end{abstract}

Aegla rosanae foi descrita por CAMPOS JR. (1998), como espécie nova, com base em um macho, coletado na Bacia do Rio Paraíba, Piquete, no Estado de São Paulo, Brasil. O autor da proposta não destaca estrutura morfológica em especial que justifique a criação da espécie.

A área de ocorrência dos anomuros de águas continentais, pertencentes ao gênero Aegla, está restrita a bacias hidrográficas do sul da América do Sul. BOND-BUCKUP \& BUCKUP (1994) ao revisarem os Aeglidae verificaram que muitas espécies podem ocorrer em mais de uma bacia hidrográfica, embora a maioria ocorra em bacias de drenagens adjacentes. Os mesmos autores ao examinarem os tipos depositados no USNM (National Museum of Natural History Smithsonian Institution, Washington, EUA), propuseram que Aegla paulensis, espécie que SCHMITT (1942) havia considerado como subespécie de A. odebrechtii Müller, 1876, fosse elevada ao status de espécie.

O exame de exemplares de Aegla depositados no Museu de Zoologia da Universidade de São Paulo, especificamente o holótipo de A. rosanae Campos Jr., 1998, ensejou a comparação dos caracteres específicos que definem a espécie.

\section{MATERIAL E MÉTODOS}

Durante as investigações que precederam a publicação da revisão monográfica das espécies de Aegla, os autores BOND-BUCKUP \& BUCKUP, tiveram a oportunidade de examinar o material tipo de A. paulensis, USNM 80023, holótipo macho, e USNM 169112, parátipo fêmea. A descrição e as representações gráficas dos caracteres de $A$. paulensis foram comparadas com o holótipo macho (MZSP 11162 ) de A. rosanae.

1) Contribuição número 351 , do Departamento de Zoologia, Universidade Federal do Rio Grande do Sul.

2) Departamento de Zoologia, Instituto de Biociências, Universidade Federal do Rio Grande do Sul. Avenida Paulo Gama, 90040-060 Porto Alegre, Rio Grande do Sul, Brasil.

3) Bolsista Pesquisador CNPq. E-mail: ginabb@vortex.ufrgs.br 


\section{RESULTADOS E DISCUSSÃO}

As espécies do gênero Aegla apresentam um conjunto de caracteres morfológicos muitas vezes de difícil e complicada delimitação das características específicas. Aegla paulensis pode ser relacionada com as espécies que apresentam a crista palmar subretangular, escavada, e o rostro linguiforme presentes nos machos adultos. A variabilidade dos caracteres morfológicos dessa espécie é significativa nos jovens, bem destacada por BOND-BUCKUP \& BUCKUP (1994: 242).

A diagnose de A. rosanae, segundo CAMPOS JR. (1998) assemelha-se àdescrita por BOND-BUCKUP \& BUCKUP (1994) com exceção de alguns caracteres mencionados a seguir. CAMPOS JR. (1998) destaca que o espinho ântero-lateral da carapaça alcança a base da córnea. No entanto, na observação do exemplar constata-se que os pedúnculos oculares encontram-se inclinados, propiciando uma interpretação errônea dessa medida. $\mathrm{O}$ mesmo autor menciona que as proeminências epigástricas são pouco destacadas. No exame do material, constata-se ainda que a descrição não é correta, pois essas estruturas são destacadas e turberculiformes, de maneira que, em vista lateral da porção anterior da carapaça, projetam-se nitidamente. Finalmente, a característica referente a margem interna da face ventral do ísquio do quelípodo que possui, segundo a diagnose de Campos Jr., "dois espinhos cônicos em posição distal", não pode ser observada no quelípodo do exemplar. Essa estrutura possui um espinho cônico distal e dois a três tubérculos em posição medial e proximal.

Cabe, ainda, um esclarecimento com relação as representações gráficas de A. rosanae. A figura 3 , da página 138 , relativa ao quelípodo maior está em vista ventral, maneira não usual, o que inviabiliza a identificação da crista palmar, que se apresenta subretangular e escavada, típica de A. paulensis. Por outro lado, BOND-BUCKUP \& BUCKUP (1994: 242) destacam com relação a A. paulensis que “... alguns exemplares possuem a crista palmar separada em lóbulos...", o que foi constatado no exemplar examinado. Igualmente está prejudicada nessa representação gráfica toda a ornamentação da vista dorsal do carpo e da crista carpal. $\mathrm{O}$ desenho 4, na mesma página, relativo ao cefalotórax em vista lateral, também encontra-se pouco representativo, uma vez que o rostro não é deflexo, mas, pelo contrário, na porção apical o rostro é moderamente recurvado para cima.

Com apoio nas características acima destacadas e, considerando, que o exemplar de $A$. rosanae apresenta o conjunto de caracteres morfológicos que a identificam como nos limites já conhecidos da natural variabilidade de A. paulensis, deve-se considerar $A$. rosanae syn.n. júnior.

AGRADECIMENTOS. Ao Dr. Gustavo S. de Melo, curador da coleção de Crustáceos do Museu de Zoologia da USP, pela cedência dos lotes de Aegla.

\section{REFERÊNCIAS BIBLIOGRÁFICAS}

Bond-Buckup, G. \& L. Buckup. 1994. A Familia Aeglidae (Crustacea, Decapoda, Anomura). Arq. Zool., São Paulo, 32 (4): 159-346.

Campos Jr., O. 1998. Nova espécie do gênero Aegla da Bacia do Rio Paraíba, Brasil (Anomura, Aeglidae). Iheringia, Sér. Zool., Porto Alegre, 85: 137-140.

Schmitt, W.L. 1942 The species of Aegla, endemic south american fresh-water crustaceans. Proc. U.S. natn. Mus., Washington, 91 (3132): 431-524.

Recebido em 19.VIII.1999; aceito em 10.IV.2000. 